\title{
Effect of Effervescent Biofertilizer Consortial Tablets on Growth of Tomato (Lycopersicon esculentum Mill.)
}

\author{
Sneha S. Nair* and G.P. Brahmaprakash \\ Department of Agricultural Microbiology, UAS, GKVK, Bengaluru-560065, Karnataka, India \\ *Corresponding author
}

\section{A B S T R A C T}

A new formulation of effervescent tablets containing microbial consortium was prepared for tomato with an objective to improve its survival and effectiveness.

Keywords

Effervescent,

Tablets,

Biofertilizers.

\section{Article Info}

Accepted:

04 July 2017

Available Online:

10 September 2017
Three agriculturally beneficial microorganisms viz. Azotobacter chroococcum, Pseudomonas fluorescens and Bacillus megaterium were used in consortium. Tablets were prepared using wet granulation method using talc or compost as diluent. Effectiveness of these inoculants formulations was studied in tomato (Lycopersicon esculentum Mill.) in a greenhouse. Maximum nitrogen, phosphorus, total chlorophyll and dry weight were observed in plants treated with compost based tablets containing triple inoculants. Improved nutrient uptake and total biomass were recorded in all plants receiving tablet based formulation compared to conventional control. Plant growth in inoculated treatments was robust when supplied with NPK fertilizers, however, higher plant biomass and nutrient uptake were observed in plants receiving triple inoculants consortium without nutrients (NPK) compared to un-inoculated plants with nutrients (+NPK).

\section{Introduction}

Tomato (Lycopersicon esculentum Mill.) is an important vegetable crop worldwide. Aside from being tasty and nutritious, they are a good source of vitamins $\mathrm{A}$ and $\mathrm{C}$ and lycopene content. Hence, this crop is gaining importance both in developing and developed countries and efforts are being made for the quality and quantity production of this commodity (Mahajan and Singh, 2006).

Addition of beneficial microorganisms in the form of biofertilizers to the soil has found to help replenish soil health thereby increasing plant growth and crop yield.
Biofertilizers are products of selected beneficial live microorganisms which when applied to the seed, plant surface or soil colonize the rhizosphere or interior of the plant and promote growth by converting nutritionally important elements from unavailable to available form through biological processes (Rokhzadi et al., 2008). Besides accessing nutrients, they also promote plant growth and control soil borne diseases. These agriculturally beneficial microorganisms help in effectively utilizing chemical fertilizers and attaining higher yield rates. 
Different types of biofertilizers such as nitrogen fixers, phosphate solubilizers, phosphorus mobilizers, plant growth promoters and bio control agents are being used in agriculture. Presently, there is no single inoculant formulation which can provide all beneficial effects together to the plant. Plant growth enhancement due to the inoculation of a combination of microbial strains has been reported to synergistically work together and promote plant growth (Pandey and Maheswari, 2007) when compared to single inoculants thereby mitigating inconsistency in their performance but the unpredictability in the performance of the consortia in soil remains a major concern.

Bacteria introduced to the soil may fail to establish in sufficient numbers in the rhizosphere because of competition from native microflora and environmental conditions. Therefore the microbial consortia should be efficiently formulated which ultimately determines the success of a biological agent (Brahmaprakash and Sahu, 2012).

Formulations typically consist of establishing viable bacteria in a suitable carrier together with an additive that aid in stabilization and protection of microbial cells during storage, transport and at the target site. Carrier based inoculants are the most common type of formulation used today but a low shelf life, inability to survive under adverse environmental conditions and a high possibility of contamination during bulk sterilization makes these formulations undesirable for the present environmental conditions. Therefore there is a need for an alternative formulation which may enhance the survival of microbial inoculants to overcome the constraints.

Effervescent tablets are a new approach in the field of biofertilizers. Tablet is defined as a compressed solid dosage form containing medicaments with or without excipients. Effervescent tablet is a type of tablet designed to produce a solution rapidly with the release of carbon dioxide. The tablets are prepared by compressing the active ingredient with mixture of organic acids such as citric acid or tartaric acid and sodium bicarbonate.

Tablets remain popular as a dosage in pharmaceutical industry due to its simplicity in preparation, stability and convenience in packing and easy dispersion.

Tablets have very less moisture content for a contaminant microorganism to multiply in the formulation during storage period. This gives an obvious advantage of purity and protection to the inoculant microorganisms in the tablet. Effervescent tablets provide an additional benefit of quick and easy release of microorganisms into the soil.

\section{Materials and Methods}

\section{Preparation of effervescent biofertilizer tablets}

Tablets were prepared using different excipients namely, diluents, binders, glidants and disintegrants. Talc and compost were selected as diluents. The tablets were prepared following wet granulation method and a rotary tablet press was used for the purpose of tablet making (Plate 1). These formulations were made in nine treatment combinationsT1 (Absolute control), T2 (Conventional control) T3 (Azotobacter chroococcum), T4 (Pseudomonas fluorescens), T5 (Bacillus megaterium), T6 (Azotobacter chroococcum + Pseudomonas fluorescens), T7 (Azotobacter chroococcum + Bacillus megaterium), T8 (Pseudomonas fluorescens + Bacillus megaterium) and T9 (Azotobacter chroococcum + Pseudomonas fluorescens + Bacillus megaterium). 
A pot experiment was conducted in green house of UAS, GKVK, Bengaluru using nine different treatments to study the performance of the inoculants on the growth of tomato (cv. Arka Rakshak). The experiment comprised nine treatments with two levels of fertilizers (with and without NPK), two levels of effervescent tablets (talc and compost based) and three replications each. Un-inoculated pots were kept as absolute control and pots treated with talc based powder formulation were kept as conventional control.

\section{Raising the nursery}

The seeds of tomato were sown in protrays filled with cocopeat. The protrays were treated with 1 tablet/slot (talc or compost based formulation). After germination, 21-25 days old seedlings were transplanted to polybags.

\section{Transplanting and maintenance}

The seedlings were transplanted to poly bags containing five kilograms of homogenized soil. Recommended dose of fertilizers were provided to + NPK pots. The poly bags were uniformly watered regularly to maintain moisture at field capacity and other routine care was taken to protect the plants from pests and diseases.

\section{Nutrients}

Nutrients in the ratio of 180: 120: 180 $\mathrm{NPK} / \mathrm{kg} / \mathrm{ha}$ were provided. Two levels of nutrients were maintained in the experiment. Fifty four pots were provided with fertilizers (+NPK) and 54 pots without fertilizers (NPK).

\section{Chlorophyll content}

Chlorophyll content was recorded at maximum vegetative growth. Estimation of chlorophyll was done by method suggested by Witham et al., (1971).

\section{Dry weight of plant}

Harvesting was done at 50 per cent flowering. Shoot and root dry weight was recorded after drying the samples at $60{ }^{\circ} \mathrm{C}$ to a constant weight. Shoots were harvested by separating stem at the collar region from roots.

Roots were washed free of soil particles by a slow jet of water.

\section{Nitrogen estimation in plant samples}

Concentration of nitrogen in root and shoot was estimated by micro kjeldahl method as outlined by Jackson (1973).

\section{Phosphorus estimation in plant samples}

The procedure outlined by Black (1965) was used to determine the phosphorus concentration in shoots and roots of tomato.

\section{Statistical analysis}

Statistical analysis of the data from greenhouse investigation was done by using factorial complete randomized design (FCRD) and means were separated by Least Significant Difference (LSD) ((Little and Hills, 1978).

\section{Results and Discussion}

\section{Total nitrogen content}

Highest total nitrogen content (mg/plant) was observed in plants receiving NPK and compost based tablets containing triple inoculants (666.14 mg/plant) followed by plants treated with NPK and talc based tablets containing triple inoculants $(631.26 \mathrm{mg} / \mathrm{plant})$ when compared to absolute control (158.07 
$\mathrm{mg} / \mathrm{plant}$ ) and conventional control (193.33 mg/plant) (Fig. 1).

Plants treated with compost based tablets showed significantly higher total nitrogen content compared to plants treated with talc based tablets. This shows that diluents influence the release of inoculants into the soil and their effective colonization. An interaction effect was observed within the plants treated with tablets with two different diluents as well as plants treated with and without fertilizers.

There was a marginal difference observed between plants treated with NPK when compared to those without NPK. However, plants receiving triple inoculants without nutrients recorded significantly higher nitrogen content (578.02 $\mathrm{mg} /$ plant) when compared to un-inoculated plants with nutrients $(158.07 \mathrm{mg} / \mathrm{plant})$.This might be due to the nitrogen fixing ability of Azotobacter chroococcum in combination with $\mathrm{N}$ fertilizers which increased the fertilizer $\mathrm{N}$ efficiency by increasing $\mathrm{N}$ content and $\mathrm{N}$ uptake in plants (Kumar and Chandra, 2008).

All treatments with NPK showed significantly higher nitrogen compared to -NPK. The possible mechanism of accumulation of more nitrogen in plants might be nitrogen fixation by Azotobacter chroococcum delivering nitrogen to plants and the production of phytohormone like substances by $P$. fluorescens that might have altered plant growth and morphology resulting in the increased nitrogen accumulation in inoculated plants (Mrkovachi and Milic, 2001).

\section{Total phosphorus content}

Highest total phosphorus content (mg/plant) was observed in plants receiving NPK and compost based tablets containing triple inoculants $(200.12 \mathrm{mg} / \mathrm{plant})$ followed by -
NPK plants treated with compost based containing triple inoculants $(181.10 \mathrm{mg} / \mathrm{plant})$ (Fig. 2). All treatments showed significantly higher phosphorus content when compared to absolute control (42.89 $\mathrm{mg} / \mathrm{plant})$ and conventional control (53.08 mg/plant).

The increase in phosphorus uptake by the plants might be due to the increase in phosphorus solubilization by the Phosphate Solubilizing Bacterium (PSB) Bacillus megaterium in the consortium.

A three way interaction effect was observed between treatments, diluents and fertilizers which denote that different diluents and application of NPK affects the inoculants thereby resulting in significant difference between the treatments. Higher phosphorus content was observed in plants treated with NPK. This might be due to combined stimulating effect of phosphate dissolving bacteria and $\mathrm{P}$ fertilizer levels in supplying the growing plants with their phosphorus requirements. However, plants receiving triple inoculants without nutrients recorded a significantly higher phosphorus content (181.06 mg/plant) compared to un-inoculated plants with nutrients $(42.89 \mathrm{mg} / \mathrm{plant})$. These results are in line with the studies of Elhami $e t$ al., (2007) who believed that the phosphorus deficiency is compensated by PSB in the absent of chemical phosphate fertilizers.

Treatments containing Bacillus megaterium recorded higher phosphorus content compared to all other treatments. The PSB treatment might have increased phosphate availability in the soils which in turn helped better proliferation of root growth and uptake of other nutrients to a greater extent. These results are in agreement with studies conducted by Nanthakumar and Veeraraghavathatham (2000); Amburani and Manivannan (2002); Prabhu et al., (2003); and Wange and Kale (2004). 
Fig.1 Total Nitrogen (mg/plant) as influenced by inoculation of effervescent biofertilizer tablets in tomato

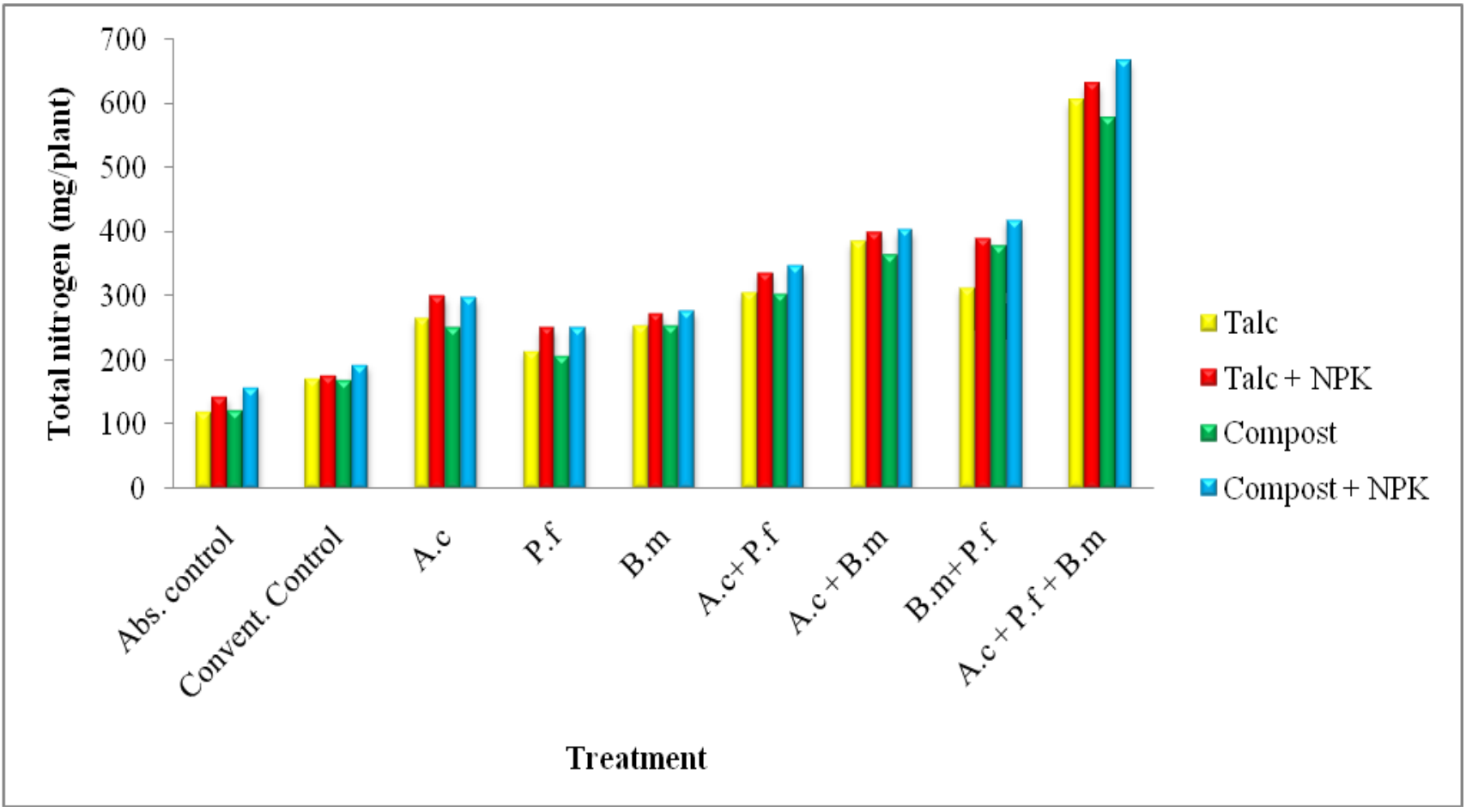

Note: A.c: Azotobacter chroococcum P.f: Pseudomonas fluorescens, B.m: Bacillus megaterium

Fig.2 Total Phosphorus (mg/plant) as influenced by inoculation of effervescent biofertilizer tablets in tomato

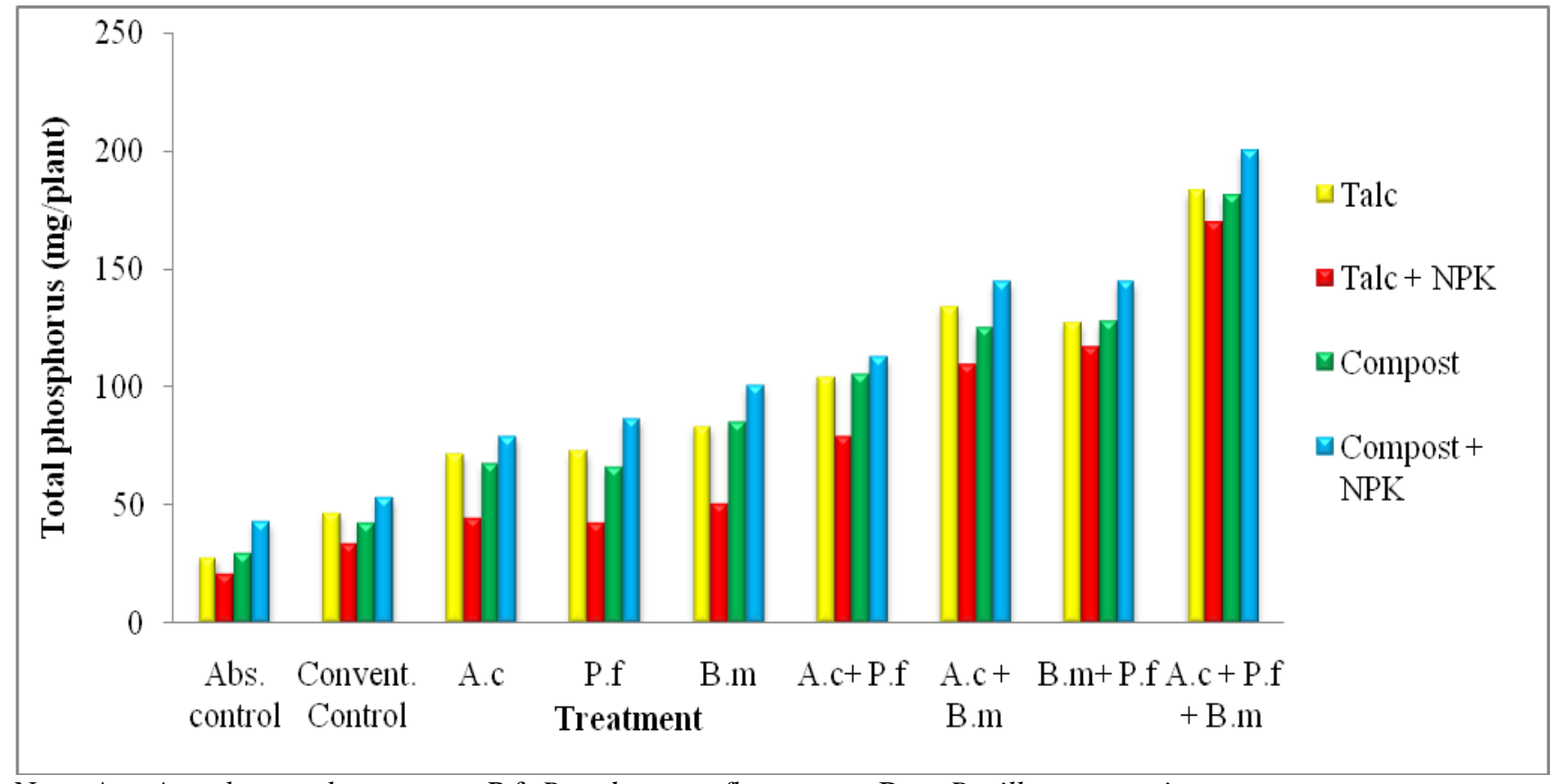

Note: A.c: Azotobacter chroococcum P.f: Pseudomonas fluorescens, B.m: Bacillus megaterium 
Fig.3 Chlorophyll content (mg/g of leaf) as influenced by inoculation of effervescent biofertilizer tablets in tomato

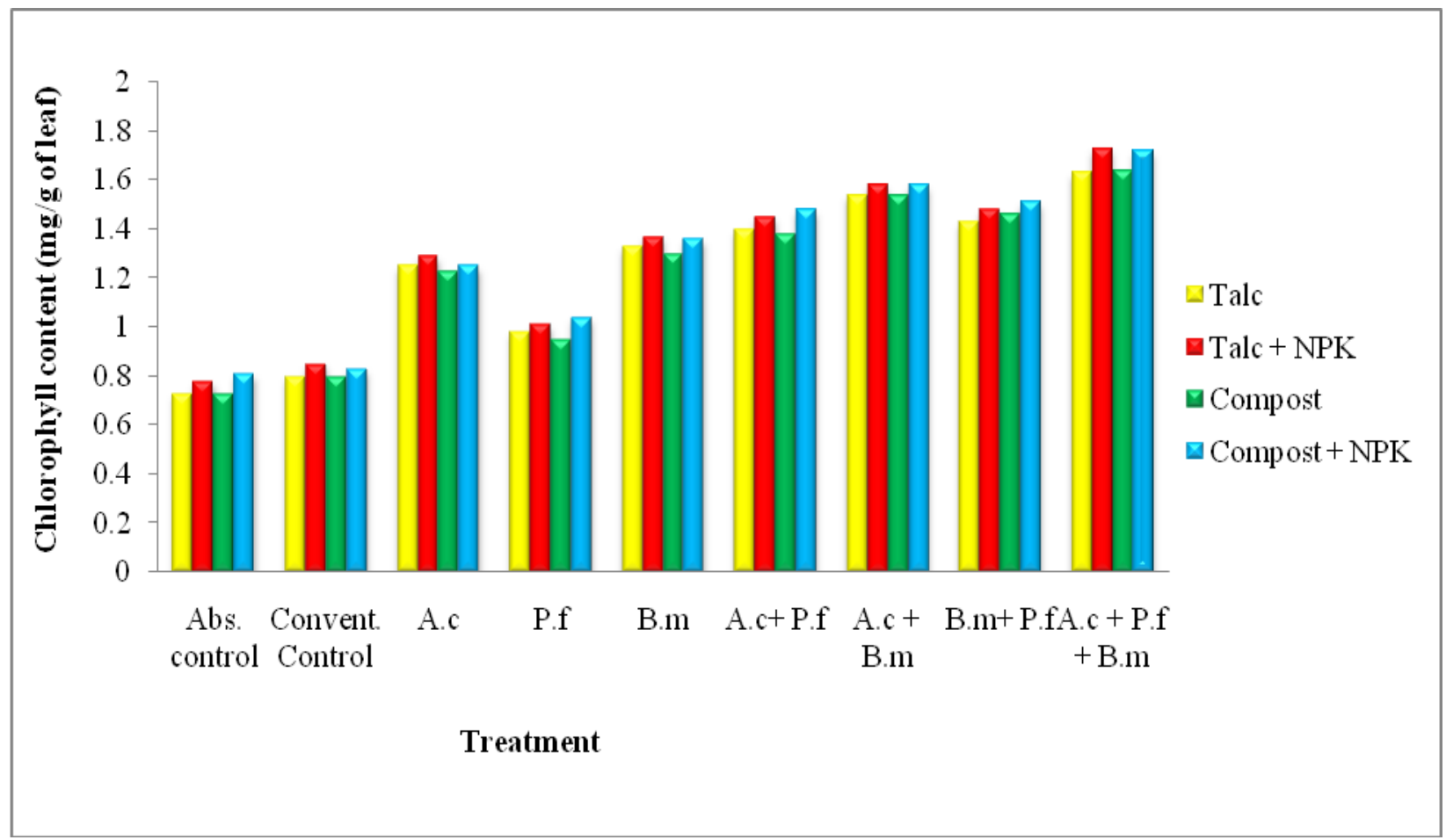

Note: A.c: Azotobacter chroococcum P.f: Pseudomonas fluorescens, B.m: Bacillus megaterium

Fig.4 Total dry weight (g/plant) as influenced by inoculation of effervescent biofertilizer tablets in tomato

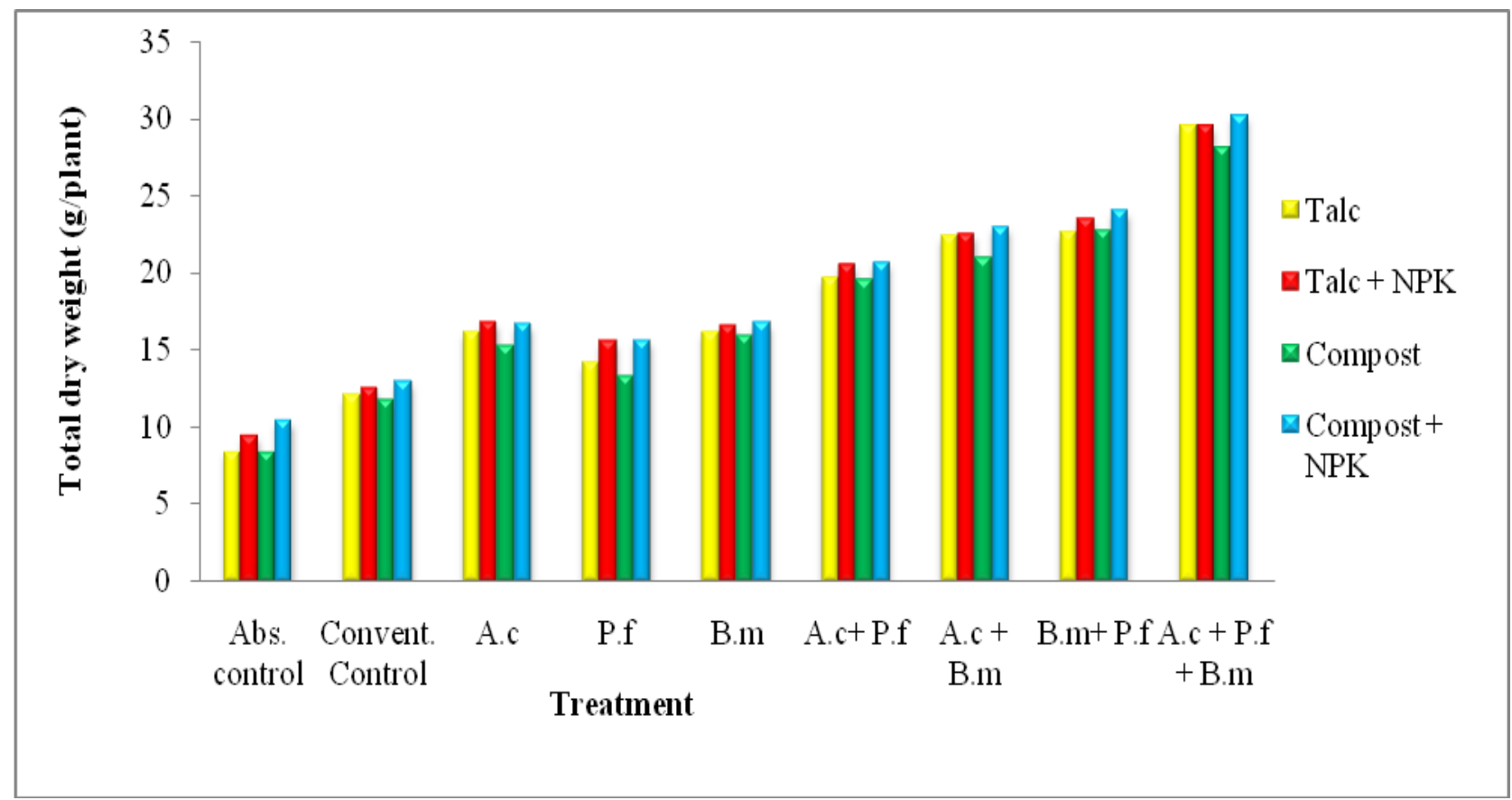

Note: A.c: Azotobacter chroococcum P.f: Pseudomonas fluorescens, B.m: Bacillus megaterium 


\section{Plate.1 Effervescent biofertilizer tablets}

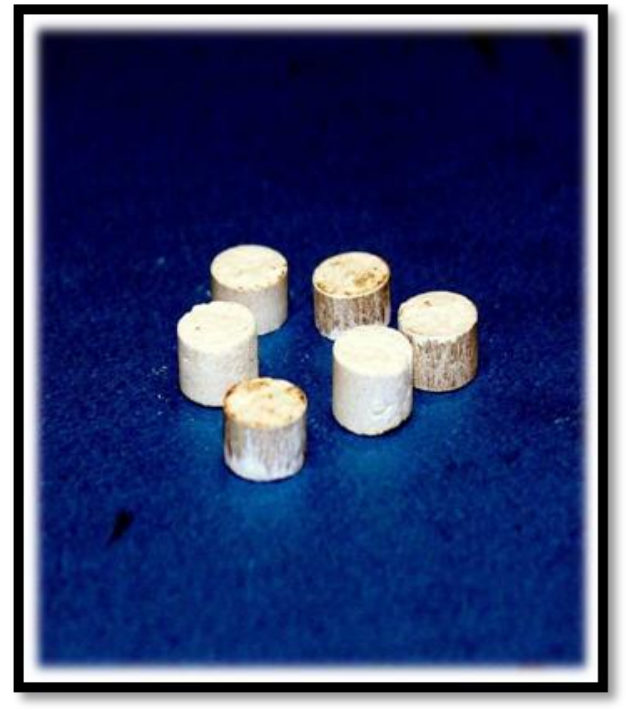

Effervescent talc tablet

\section{Total chlorophyll content}

Plants treated with triple consortia recorded maximum chlorophyll content $(1.68 \mathrm{mg} / \mathrm{g}$ of leaf) followed by dual inoculants Azotobacter chroococcum and Bacillus megaterium (1.56 $\mathrm{mg} / \mathrm{g}$ of leaf) and Bacillus megaterium and $P$. fluorescens (1.51 mg/g of leaf). The least chlorophyll content was observed in absolute control $(0.76 \mathrm{mg} / \mathrm{g}$ of leaf) followed by conventional control $(0.82 \mathrm{mg} / \mathrm{g}$ of leaf) (Fig. $3)$. Among single inocula, plants receiving $A$. chroococcum recorded maximum chlorophyll $(1.25 \mathrm{mg} / \mathrm{g}$ of leaf). Higher chlorophyll content in triple inoculants may be due to the synergistic effects of Pseudomonas fluorescens and $B$. megaterium on $A$. chroococcum which resulted in higher uptake of nitrogen. These results are on par with the findings of Sulejman et al., (2006) and Bambara and Ndakidemi (2009).

A significantly higher total chlorophyll content was observed in plants treated with NPK $(1.28 \mathrm{mg} / \mathrm{g}$ of leaf) compared to those without $(1.23 \mathrm{mg} / \mathrm{g}$ of leaf). This might be due to the interaction of inorganic fertilizers and biofertilizer which enhanced absorption

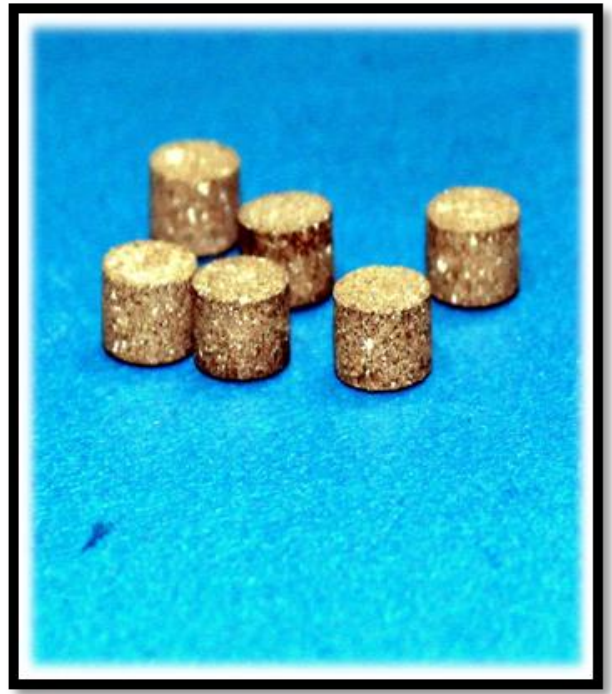

\section{Effervescent compost tablet}

of nutrients and effective conversion of the nutrients into pigments and resulted in accumulation of more chlorophyll in the leaves. The results are in accordance with the findings of Hellal et al., (2011).

\section{Dry weight of plants}

Highest total dry matter content was observed in plants receiving compost based tablets containing triple inoculants and NPK (30.2 g/plant) followed by plants treated with NPK and talc based containing triple inoculants (29.56 g/plant) when compared to absolute control (10.44 g/plant) and conventional control (12.94 g/plant) (Fig. 4). High dry weight in plants receiving triple inoculant tablets might be due to the interaction effects of nitrogen fixing microorganisms, phosphate solubilizing microorganism and PGPR microorganism with each other by providing nutrients increase the crop growth. Previous studies have reported that co-inoculation with microbes has been found to perform better than with individual isolates (Pandey and Maheshwari 2007; Szczech and Dys'ko 2008). This study corroborates these earlier findings. 
A three way interaction effect was observed between microbial inoculants and fertilizers. All treatments receiving NPK yielded higher shoot dry weight when compared to those without NPK. However a significantly lower plant dry weight was observed in uninoculated + NPK plants (10.44 g/plant) compared to triple inoculated plants without NPK (28.13 g/plant) which shows the efficiency of the inoculants to effectively supply sufficient nutrient to the plant.

Dry weight of a plant includes the nutrient present in the plant tissue. High dry weight indicates good photosynthetic efficiency of the plants. In this study all plants receiving tablet formulation showed higher total dry weight which denotes the effectiveness of the tablets over conventional biofertilizers.

It was concluded that all plants treated with effervescent biofertilizer consortial tablets showed a pronounced and significantly higher nutrient uptake, chlorophyll content and total dry matter compared to absolute control and conventional control. The effervescence from the tablet might have positively affected the early and quick release of microorganisms into the rhizosphere thereby resulting in effective colonization by the inoculants.

Improved nutrient uptake and total biomass were recorded in all plants receiving tablet based formulation compared to conventional control which signifies the effective release and colonization of microbial inoculants in tablet based formulations compared to conventional control.

Preliminary success made by this study encourages further investigation on tablet based formulations. Research is needed to set up a protocol for preparation of tablets with higher initial microbial population in and increasing the size of the tablet that will decrease the compression force on the tablets.

\section{Acknowledgement}

The author would like to express her profound gratitude and sincere thanks to Dr. K. B. Suresh (AICRP on Post-Harvest Engineering and Technology) for providing her with necessary facilities for the present investigation.

\section{References}

Amburani, A., and Manivannan K. 2002. Effect of integrated nutrient management on growth in brinjal (Solanum melongena L.) cv. Annamalai. South Indian Hort., 50 (46): 377-386.

Bambara, S., and Ndakidemi P. A. 2009. Effects of Rhizobium inoculation, lime and molybdenum on nitrogen fixation of nodulated Phaseolus vulgaris L. Afr. J. Microbiol. Res., 4 (9): 682-696.

Black, C.A., 1965. Method of soil analysis part II Agronomy Monograph No. 9. Am. Soc. Agron., Madison, Wisconsin, pp. 148.

Brahmaprakash, G.P., and Sahu P. K. 2012. A review: Bio-fertilizers for sustainability. J Indian Institute Sci., 92 (1): 37-62.

Elhami, F.M., Jafari S. and Nadian H. A. 2007. Effect of mycorrhiza inoculation and phosphorous solubilizing on phosphorus consume and growth of Phragmatis. Proceeding of 10th Congress of Soil Science, Karaj, Iran.

Hellal, F.A., Abdelhameid M., Doaa J., AboBasha M. and Zewainy, R. M. 2012. Alleviation of the adverse effects of soil salinity stress by foliar application of silicon on faba bean (Vicafaba L.). J. Appl. Sci. Res., 8 (8): 4428-4433.

Jackson, M.L., 1973. Soil Chemical Analysis, Prentice Hall of India Pvt. Ltd., New Delhi. pp. 485.

Kumar, R., and Chandra R. 2008. Influence of PGPR and PSB on Rhizobium 
leguminosarum bv. viciae strain competition and symbiotic performance in lentil. World J. Agri. Sci., 4: 297-301.

Little, T.M., and Hills J. F. 1978. Agricultural experimentation. John Wiley and sons, New York, USA.

Mahajan, G., and Singh K. G. 2006. Response of greenhouse tomato to irrigation and fertigation. Agricultural Water Management, 84: 202-206.

Mrkovacki, N., and Milic V. 2001. Use of Azotobacter chroococcum is potentially useful in agricultural application. Ann. Microbiol., 51: 145-158.

Nanthakumar, S., and Veeraraghavathatham D. 2000. Effect of integrated nutrient management on growth parameters and yield of brinjal (Solanum melongena $\mathrm{L}$.) cv. PLR-1. South Indian Hort., 48: 3135.

Pandey, P., and Maheshwari D. K. 2007. Two-species microbial consortium for growth promotion of Cajanus cajan. Curr. Sci., 92: 1137-1142.

Prabhu, M., Veeraraghavathatham D. and Srinivasam K. 2003. Effect of nitrogen and phosphorous on growth and yield of brinjal hybrid COBH-1. South Indian
Hort., 51 (1-6): 152-156.

Rokhzadi, A., Asgharzadeh A., Darvish F., Nourmohammadi G. and Majidi E. 2008. Influence of plant growthpromoting rhizobacteria on dry matter accumulation and yield of chickpea (Cicer arietinum L.) under field condition. Am. Eur. J. Agric. Environ. Sci., 3: 253- 257.

Sulejman, R., Josip C., Mihael A., Milan P., Marija P., Sanja S. and Miranda S. 2006. Effect of inoculation and growth regulator on soybean yield and photosynthetic pigment content. Agric. Conspec. Sci., 71 (3): 75-80.

Szczech, M., and Dys'ko J. 2008. The possibility to use selected mixtures of PGPR bacteria in tomato cultivation. Veg. Crop Res. Bull., 68: 47-56.

Wange, S.S., and Kale R. H. 2004. Effect of bio-fertilizers under graded nitrogen levels on brinjal crop. J. Soils. Crops, 14 (1): 9-11.

Witham, F.H., Blaydes D. F. and Devlin R. M. 1971. Experiments in Plant Physiology, Van Nostrand, New York, pp 245.

\section{How to cite this article:}

Sneha S. Nair and Brahmaprakash, G.P. 2017. Effect of Effervescent Biofertilizer Consortial Tablets on Growth of Tomato (Lycopersicon esculentum Mill.). Int.J.Curr.Microbiol.App.Sci. 6(9): 615-623. doi: https://doi.org/10.20546/ijcmas.2017.609.076 